\section{Carbon isotopes and carbon cycling}

BIOGEOCHEMICAL processes that can change atmospheric $\mathrm{CO}_{2}$ and the ocean-atmosphere distribution tend to fit into two categories (see figure): biological-pump increases which involve greater sinking fluxes of organic carbon relative to upwelling of total $\mathrm{CO}_{2}$; and subsurface rearrangement, where a change in ocean circulation or vertical distribution of organic matter reoxidation actuates a transfer of nutrients and total $\mathrm{CO}_{2}$ to greater depths ${ }^{5}$. Processes producing this vertical shift are sometimes called alkalinity mechanisms, because the downward shift of metabolic $\mathrm{CO}_{2}$, currently concentrated at intermediate depth, produces a transient increase in calcium carbonate through dissolution at the ocean floor, and it is this characteristic which reduces the atmospheric $\mathrm{CO}_{2}$. But ocean alkalinity also increases in response to an increased biological pump as well as to decreases in biological production of calcium carbonate at the surface. In the case of decreased carbonate production, the ocean isotope composition is virtually unchanged, and one cannot in-

preindustrial climate, more than twice what can be accounted for by the $0.4 \%$ change in surface-deep-ocean carbon isotope gradient.

One way out of this fix is if the ice-age air-sea exchange fractionation is more effective than expected from average sea-surface temperature. Then the atmospheric results allow a more positive ocean surface $\delta^{13} \mathrm{C}$ and a greater vertical ocean gradient. Marino et al. show that this works if more of the gas exchange occurred through the cold polar ocean, especially if these waters decreased their $\delta^{13} \mathrm{C}$ by as much as $1 \%$, as indicated by measurements ${ }^{7}$ from the planktonic foraminifera, Neogloboquadrina pachyderma. This decrease would be consistent with decreased productivity in southern-ocean waters inferred from opal accumulation rates and $\mathrm{Ge} / \mathrm{Si}$ ratios $^{8}$.

In the model of Marino et al., an increase in the low-latitude biological pump, in the exchange of upper ocean water and a near cessation of highlatitude productivity apparently combine to produce a decrease in atmospheric $\mathrm{CO}_{2}$ and a change in ocean-atmosphere $\delta^{13} \mathrm{C}$ similar to that deduced from glacial proxies. But as loss of productivity would allow high $\mathrm{CO}_{2}$ partial pressure to surface in the surface ocean, it is not clear how exhalation of isotopically light $\mathrm{CO}_{2}$ into the atmosphere would decrease atmospheric $\delta^{13} \mathrm{C}$ without pumping the atmospheric $\mathrm{CO}_{2}$ content back up again.

The differing $\delta^{13} \mathrm{C}$ values at the sea surface and in deep waters are a result of fer changes in ocean alkalinity from the $\delta^{13} \mathrm{C}$ distribution.

Both biological-pump and subsurfacerearrangement processes preferentially transfer ${ }^{12} \mathrm{C}$ over ${ }^{13} \mathrm{C}$ to the deep ocean and increase the $\delta^{13} \mathrm{C}$ gradient from surface to deep ocean. The main difference is in where the ${ }^{12} \mathrm{C}$ is shifted from. Increases in the biological pump further deplete the light isotope from the surface ocean and the atmosphere because of gas exchange. Simple subsurfacerearrangement mechanisms, such as deeper recycling of particulate organic matter, transfer the ${ }^{12} \mathrm{C}$ exclusively from intermediate to deep waters, and the isotope ratio in the surface ocean and atmosphere is unaffected. In models with a polar outcrop of cold water, a subsurface rearrangement due to increased upwelling in the upper ocean may transfer light carbon out of the surface and intermediate waters, because the warm-ocean biological pump of ${ }^{12} \mathrm{C}$ from the surface becomes stronger in relation to the 'leak' of light carbon out of the cold surface ocean and back into the warm ${ }^{6}$

R.K.

the differing roles of dissolved $\mathrm{CO}_{2}$ and of organic matter produced by phytoplankton. The reduced partial pressure of $\mathrm{CO}_{2}$ during the last ice age, it has been suggested ${ }^{9}$, would alter the fractionation by biotic processes, invalidating the constant organic contribution built into the model calculations. Leuenberger et al. show that this variation could offset some of the increased $\delta^{13} \mathrm{C}$ gradient expected from the simple biological pump and subsurface rearrangement mechanisms.

Deciphering the mechanism of atmospheric $\mathrm{CO}_{2}$ change from the changes in carbon isotope distributions is a difficult game using small numbers, painstakingly obtained. What is evident from the results in this issue is that it is hard to explain the low ice age $\mathrm{CO}_{2}$ solely using carbon-fractionating mechanisms.

Robin Keir is at GEOMAR, ChristianAlbrechts University, $2300 \mathrm{Kiel} 14, \mathrm{Ger}$ many.

1. Marino, B. D., McElroy, M. B., Salawitch, R. J. \& Spaulding, W. G. Nature $357,461-466$ (1992)

2. Leuenberger, M., Siegenthaler, U. \& Langway, C. C. Nature 357, 488-490 (1992)

3. Curry, W. B., Duplessy, J. C., Labeyrie, L. D. \& Shackleton, N. J. Paleoceanography 3, 317-341 (1988).

4. Broecker, W. S. \& Peng, T.-H. Radiocarbon 28, 309-327 (1986)

5. Boyle, E. A. J. geophys. Res. 93, 15,701-15,714 (1988)

Keir, R. S. Global biogeochem. Cycles 5, 351-358 (1991)

7. Labeyrie, L. D. \& Duplessy, J. C. Palaeogeog. Palaeoclim. Palaeoecol. 50, 217-240 (1985)

8. Mortlock, R. A. et al. Nature 351, 220-223 (1991).

9. Rau, G. H., Takahashi, T. \& Des Marais, D. J. Nature 341, 516-518 (1989)

\section{Water music}

MATTER absorbs light on strict quantum principles. A molecule absorbs a photon most readily if It has Just the right energy to raise that molecule to some allowed excited state. So, says Daedalus, a llquid molecule should be neatly evaporated by a photon which exactly supplies its latent heat of evaporation. For water at room

temperature, for example, this 'resonant evaporation' should be Induced by photons of wavelength $\mathbf{2 . 7 1}$ micrometres, in the infrared. Water Indeed absorbs strongly in this region.

Resonant evaporation, says Daedalus, has absolutely no thermal inertia. The photon must evaporate the recelving molecule instantly. A modulated infrared laser, tuned to $\mathbf{2 . 7 1}$ micrometres and almed at a water surface, would vaporize it in precise synchronism to that modulation. Water expands strongly on evaporation; so pressure pulses exactly following the modulation would propagate into the atmosphere. If the modulation was in the audio band, the water would speak up in high fidelity.

The result is a loudspeaker with no moving parts. Its frequency extends from the deepest bass far Into the ultrasonlc region. Best of all, It generates its sound from an exact location - the point where the beam enters the water surface. At a stroke, it solves the whole problem of stereo reproduction.

A conventional two-track stereo recording is only an approximation of the original multi-track master recording, on which each Instrument has its own track. But 'resonant evaporation stereo' could reproduce the master exactly. A bank of Infrared lasers facing a damp wall, each driven from one instrumental track and aimed at the true position of that instrument, could bring the original concert to life In full spatial detall on that wall. (A better wetted surface would be one of those polymeric fabrics which can absorb vast amounts of free water without getting sticky.)

The hi-fl industry, in its ceaseless quest for expensive new gadgets, should welcome this complicated advance. So should the cinema. Each actor, tracked automatically and Invisibly around the new damp screen by his own sonic Infrared laser, would speak consistently from his own larynx. The stage could benefit too. Ventriloquists with damp dummies and pop stars with damp shirt fronts could engage in convincing double-talk or mime to thelr own records, with the ald of a confederate aiming an infrared laser from the balcony. Daedalus is even inventing laser-based aqua-karaoke. He reckons that a singer in the bath might rather enjoy the experlence of having the bath Joln In.

David Jones 